\title{
Multiple Genitourinary Vascular Anomalies - A Case Report
}

\section{ABSTRACT}

Diagnostic, operative and cardiovascular procedures require the knowledge of variation of blood vessels of the genitourinary system. During routine dissection in an approximately 60 years old male cadaver in the Department of Anatomy, Government Medical College, Amritsar, we came across multiple vascular anomalies involving renal and testicular arteries and veins. The right kidney was supplied by three renal arteries i.e. superior, middle and inferior which originated from abdominal aorta separately; Right testicular artery originated from inferior renal artery instead of abdominal aorta. Venous drainage comprised of three renal veins and a superior polar vein which drained into IVC, right testicular vein instead of draining into IVC drained into inferior renal vein. The left kidney was supplied by three renal arteries i.e. superior, inferior and the one which originated from posterolateral aspect of aorta above the superior renal artery. Venous drainage of left kidney comprised of two renal veins which joined to form single renal vein which received left testicular vein and coursed behind the aorta to drain into IVC thus constituting retro aortic left renal vein. Further, the outgoing and the clinical and surgical implications of these variants are discussed.

Keywords: Kidney, Renal artery, Retro aortic left renal vein, Testicular artery, Testicular vein

\section{CASE REPORT}

During the gross anatomy dissection of the abdomen of an approximately 60 years old male cadaver, following variants were seen:

\section{ON RIGHT SIDE:}

1. Right kidney was supplied by three renal arteries i.e. superior, middle and inferior

(See [Table/Fig-1]):

a) Superior renal artery $1.69 \mathrm{~mm}$ in diameter, emanated opposite the origin of superior mesenteric artery, crossed the middle one anteriorly and entered the middle part of hilum of the kidney behind the upper renal vein.

b) Middle renal artery $3.02 \mathrm{~mm}$ in diameter, emanated just below the superior renal artery, passed behind the same and entered the kidney in the upper part of the hilum.

c) Inferior renal artery $1.66 \mathrm{~mm}$ in diameter, emanated from the anterolateral aspect of aorta $1.5 \mathrm{~cm}$ below the origin of superior mesenteric artery, coursed laterally and entered lower part of the hilum behind the lower renal vein.

2. Right testicular artery:
It took origin from the inferior renal artery at the distance of $4 \mathrm{~mm}$ from later's origin [Table/Fig-1], coursed downwards behind the right renal vein to reach on medial side of right testicular vein near later's drainage into right renal vein. Then the right testicular artery crossed the right testicular vein and right ureter from medial to lateral side ,so that relation of three structures i.e. ureter, testicular vein and testicular artery were lateral to medial in upper part, posterior to anterior in middle part where crossing over occurred and medial to lateral part in lower part [Table/Fig-2], and coursed downwards towards the deep inguinal ring.

3. Venous drainage of right kidney:

- $\quad$ The venous drainage of right kidney comprised of 3 veins i.e. superior, middle and inferior renal veins. All of these emerged from hilum, and coursed anterior to renal arteries and finally drained into the IVC.

- $\quad$ Apart from these three, a superior polar renal vein was emerging at the upper pole of kidney and joining the IVC. It was just $2 \mathrm{~mm}$ in diameter.

4. Right testicular vein instead of joining IVC, joined the Inferior renal vein at right angles to the same [Table/ Fig-1].

On left side, following variants were noted [Table/Fig-3]. 
1. Two renal arteries were arising from aorta i.e. Superior and Inferior

a) Superior renal artery $2.84 \mathrm{~mm}$ in diameter emanated at the level of superior mesenteric artery, coursed in front of the renal vein and divided into 2 branches both entering the renal hilum.

b) Inferior renal artery $2.18 \mathrm{~mm}$ in diameter emanated $1.5 \mathrm{~cm}$ below the origin of superior mesenteric artery coursed in front of left renal vein and then behind its lower tributary to enter the hilum in latter's lower part.

c) Apart from the 2 main renal arteries (vide supra) another artery $1.83 \mathrm{~mm}$ in diameter emanated from the poster lateral aspect of aorta just above the superior renal artery. It passed in front of the left crus of diaphragm and entered the kidney on its medial border above the hilum.

2. Venous drainage of left kidney:

It was in the form of two veins emerging in the upper and lower part of the hilum. The upper vein passed behind both the renal arteries while lower passed anterior to lower renal arteries. After coursing a distance of $3 \mathrm{~cm}$ both the veins joined to form single renal vein. This single renal vein received left testicular vein and after a distance of $1.5 \mathrm{~cm}$ again divided into 2 renal veins i.e. upper and lower, both of the renal veins thus formed coursed to the right behind the abdominal aorta at the level of $L 2$ and L3 vertebrae respectively to drain into IVC. Thus, these constituted retro aortic left renal veins [Table/Fig-3].

\section{DISCUSSION}

Different variants as observed in the present cadaver are discussed vide infra.

a. Multiple Renal arteries on the two sides: There were 2 additional renal arteries on both the sides along with a normal renal artery. Such arteries are termed as accessory supernumerary, aberrant or additional renal arteries [1]. However, Graves [2] gave the name "accessory renal artery" to the one which arises from the aorta in addition to the main renal artery. It may be entering the kidney at its hilum or medial border or at any other point. He named the other renal arteries arising from sources other than aorta as "aberrant renal arteries". Thus, in the present case we can name these additional renal arteries as accessory renal arteries on both the sides.

[Table/Fig-4] compares the incidence of accessory renal arteries as observed by the earlier authors [1,3-10].

Its evident from [Table/Fig-4] that the incidence of Accessory renal artery varies a lot between 11-61\%. Gupta et al., [1] attributed it to the social, ethnic and racial factors. Although such a wide range of incidence of this entity is reported yet almost all the authors are silent about its bilateral representation except for Gupta et al., [1] who found bilateral ARA in 3.3\% cadavers (As was seen in the present case). So this makes this a very rare case.

\section{b. Origin of right testicular artery from accessory renal artery}

A variant origin of testicular artery is frequently reported. It may arise from renal artery, suprarenal artery or lumbar artery. The two testicular arteries may arise as a common trunk and there may be 2,3 or four arteries on one side [11]. However, a testicular artery arising as a branch of accessory renal artery is a unique observation. The gonadal artery variations are reported to be more common in males than the females and more on right side as compared to left side.

[Table/Fig-5] compares the incidence of origin of right testicular artery from renal artery as observed by earlier authors [12-17].

As evident from [Table/Fig-5] incidence of origin of right testicular artery from renal artery varies from $2.6-14 \%$ in different studies. Apart from this sporadic cases have been

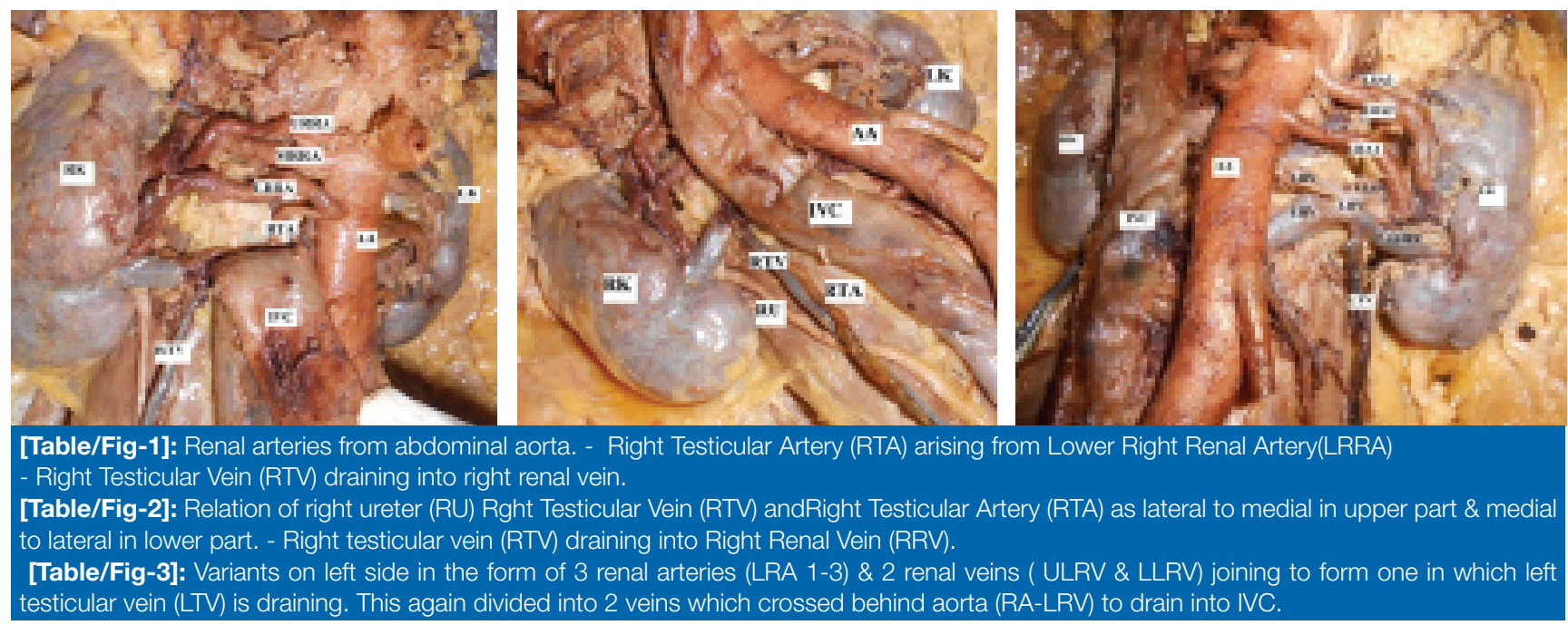




\begin{tabular}{|c|l|c|}
\hline S.No & \multicolumn{1}{|c|}{ Author (Year) } & Incidence of Accessory Renal Artery \\
\hline 1. & Rupert [3] & 61.00 \\
\hline 2. & Eisendrath [4] & 45.00 \\
\hline 3. & Anson and Kruth [5] & 20.00 \\
\hline 4. & Merklin \& Michal [6] & 30.00 \\
\hline 5. & Bregman et al., [7] & 30.00 \\
\hline 6. & Nayak [8] & 20.00 \\
\hline 7. & Saldarriaga et al., [9] & 24.90 \\
\hline 8. & Budhiraja et al., [10] & 11.66 \\
\hline 9. & Gupta et al., [11] & 28.33 \\
\hline \\
[Table/Fig-4]: Comparison of incidence of accessory renal \\
arteries.
\end{tabular}

\begin{tabular}{|c|l|c|c|}
\hline s. No & \multicolumn{1}{|c|}{ Authors } & Year & $\begin{array}{c}\text { Incidence Of Origin Of Right } \\
\text { Testicular Artery From Renal Artery }\end{array}$ \\
\hline 1. & Notkovitch [12] & 1956 & $14 \%$ \\
\hline 2. & Lippert and Pabst [13] & 1985 & $6.0 \%$ \\
\hline 3. & Ravery et al., [14] & 1993 & $5-6 \%$ \\
\hline 4. & Asala et al., [15] & 2001 & $2.6 \%$ \\
\hline 5. & Cicakcibasi et al., [16] & 2002 & $5.5 \%$ \\
\hline 6. & Pai et al., [17] & 2008 & $7.4 \%$ \\
\hline
\end{tabular}

[Table/Fig-5]: Showing incidence of origin of right testicular artery from renal artery.

reported by Bordie et al., [18], Sylvia et al., [19], Soni and Wadhwa [20] and Magotra et al., [21]. Machnicki and Grzybiak [22] classified origin of testicular artery into 4 types as follows.

Type -I - A single testicular artery arising from aorta.

Type- II - A single testicular artery arising from renal artery.

Type- III - Two testicular arteries arising from aorta and penetrating the same gonad.

Type -IV - Two testicular arteries for same gonad with one arising from aorta and other from the renal artery.

Thus our variant falls in Type II of Machnicki and Grzybiak [22] classification.

\section{c. Right testicular vein joining right renal vein}

[Table/Fig-6] compares the incidence of drainage of right testicular vein into right renal vein instead of IVC [23-25].

As evident from [Table/Fig-6] the incidence of drainage of right testicular vein into right renal vein varies from $1.8 \%$ to $21.7 \%$.

\begin{tabular}{|c|l|c|c|}
\hline S. No & \multicolumn{1}{|c|}{ Authors } & Year & $\begin{array}{c}\text { Incidence of Drainage of Right } \\
\text { Testicular Vein Into Right Renal Vein }\end{array}$ \\
\hline 1. & Zumstein [23] & 1895 & $1.8 \%$ \\
\hline 2. & Pick \& Anson [24] & 1940 & $15 \%$ \\
\hline 3. & Anson et al., [25] & 1948 & $21.7 \%$ \\
\hline
\end{tabular}

[Table/Fig-6]: Incidence of drainage of right testicular vein into right renal vein.

Apart from these isolated case have also been reported by Sharma and Salwan [26].

\section{d. Multiple Right Renal Veins}

According to Pick and Anson [24] the multiple renal veins also known as supernumerary renal veins are much more common on right side as compared to left side. [Table/Fig-7] depicts incidence of supernumerary veins on right side as observed by earlier workers $[3,7,24,27,28]$.

\begin{tabular}{|c|l|c|c|}
\hline S. No & \multicolumn{1}{|c|}{ Author } & Year & $\begin{array}{c}\text { Incidence of Supernumerary Right } \\
\text { Renal Veins }\end{array}$ \\
\hline 1. & Rupert [3] & 1915 & $25.4 \%$ \\
\hline 2. & Anson et al [27] & 1936 & $11 \%$ \\
\hline 3. & Pick \& Anson [27] & 1940 & $27.8 \%$ \\
\hline 4. & $\begin{array}{l}\text { Monk house \& } \\
\text { Khallique [28] }\end{array}$ & 1986 & $7.2 \%$ \\
\hline 5. & Bergmann [7] & 2000 & $18 \%$ \\
\hline \\
[Table/Fig-7]: Showing incidence of supernumerary right renal \\
veins.
\end{tabular}

\section{e. Retroaortic Left Renal Vein}

[Table/Fig-8] depicts incidence of retro aortic left renal vein as observed by the earlier authors.

As evident from [Table/Fig-8] the incidence of retro aortic left renal vein varies from $0.5 \%$ to $22.22 \%$ in different studies [24,29-33]. Apart from this isolated cases have also been reported by Gupta and Singla [34] and Kalsey et al., [35].

The presence of variation of both the testicular arteries as well as the testicular vein is seldom seen together reported by Singh et al., [36].

\begin{tabular}{|c|l|c|c|}
\hline S. No & \multicolumn{1}{|c|}{ Author } & Year & $\begin{array}{c}\text { Incidence of Retroaortic } \\
\text { Left Renal Vein }\end{array}$ \\
\hline 1. & Pick and Anson [24] & 1940 & $3.4 \%$ \\
\hline 2. & Almagro et al., [29] & 1992 & $1.72 \%$ \\
\hline 3. & Jafarpour \& Mofid pour [30] & 2002 & $6.25 \%$ \\
\hline 4. & Mendizabal et al., [31] & 2005 & $22.22 \%$ \\
\hline 5. & Karazincir et al., [32] & 2007 & $2.2 \%$ \\
\hline 6. & Hemelatha et al., [33] & 2008 & $0.5 \%$ \\
\hline
\end{tabular}

[Table/Fig-8]: Showing incidence of retroaortic left renal vein

\section{ONTOGENY}

\section{a. Multiple right renal arteries and origin of right testicular artery from inferior renal artery}

The ontogenic development of renal and gonadal arteries from lateral mesonephric branches of the dorsal aorta is related to the individual or combined variation of both the vessels. The developing mesonephros, metanephros, suprarenal glands and gonads are supplied by nine pairs of lateral mesonephric arteries arising from dorsal aorta in an $18 \mathrm{~mm}$ fetus. These arteries were divided into 3 groups by Felix as follows: $1^{\text {st }}$ and $2^{\text {nd }}$ arteries as the cranial, the $3^{\text {rd }}$ and $5^{\text {th }}$ arteries as middle 
and $6^{\text {th }}$ and $9^{\text {th }}$ arteries as caudal group. Multiple renal arteries result due to the persistence of more than one arteries of the middle group. As stated by Felix any of these nine arteries may become the gonadal artery but usually it arises from caudal group.

In the present case, it seems that the renal arteries ( 3 on each side) developed from the middle group of lateral mesonephric arteries (i.e. $3^{\text {rd }}$ to $5^{\text {th }}$ arteries). The 6th lateral mesonephric artery was arising immediately caudal to the $5^{\text {th }}$ artery on right side.[Table/Fig-9(a)]. It developed into the right testicular artery. With the differential growth of abdominal aorta and the inferior renal artery, the origin of $6^{\text {th }}$ lateral mesonephric artery (right testicular artery) shifted to the inferior renal artery ( $A B$ in [Table/Fig- 9a and b]). The portion AB of aorta [Table Fig-9a] is incorporated in inferior renal artery in the present case

( $A B$ in [Table/Fig-9b]). That is the reason it is arising just at a distance of $4 \mathrm{~mm}$ from origin of the later.

In the present case, the ontogenic basis of right testicular vein draining into right renal vein can be explained as follows-

The right supracardinal subcardinal anastomosis and the inter-subcardinal anastomosis joined the subcardinal veins at a cranial level (Point $A$ in [Table/Fig-10]) as compared to the normal level i.e. level of joining of right renal vein (Point $\mathrm{B}$ in [Table/Fig-10]. IVC developed normally. The right renal
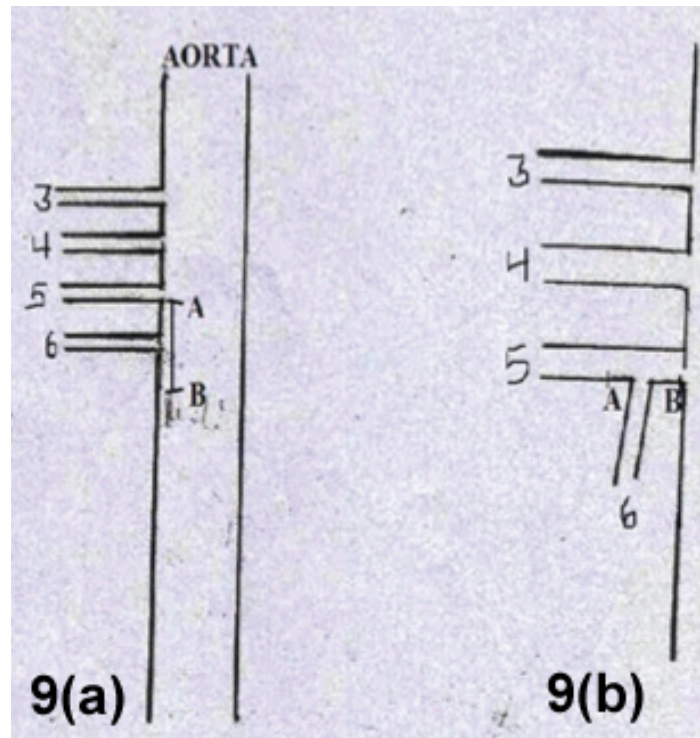

[Table/Fig-9a]: Normal development of lateral meso nephric arteries. (3-5 Middle group, 6 Caudal group which risr to testicular artery, AB- Part of aorta from which $6^{\text {th }}$ lateral mesonephric artery is arising).

[Table/Fig-9b]: Development in the present case (3-5 lateral mesonephric arteries which have persisted to form 3 renal arteries. $A B$ is apart of aorta which is giving rise to $6^{\text {th }}$ artery i.e Right testicular artry and has migrated to inferior renal arteries $\left(5^{\text {th }}\right.$ lateral mesonephric artery by its differential growth). vein developed from 2 sources, the original mesonephric vein draining kidney to subcardinal vein (BC in [Table/Fig10]) and the part of subcardinal vein between attachment of mesonephric vein and intersubcardinal anastomosis (AB in [Table/Fig 10]) and thus it drained into IVC. The right testicular vein developed normally i.e. from caudal part of right subcardinal vein caudal to attachment of mesonephric vein. Since it joined that part of subcardinal vein which forms a part of right renal vein (AB in [Table/Fig 10]), it drained into right renal vein [Table/Fig-10] Multiple right renal veins may be because of multiple mesonephric veins draining to subcardinal vein and their persistence.

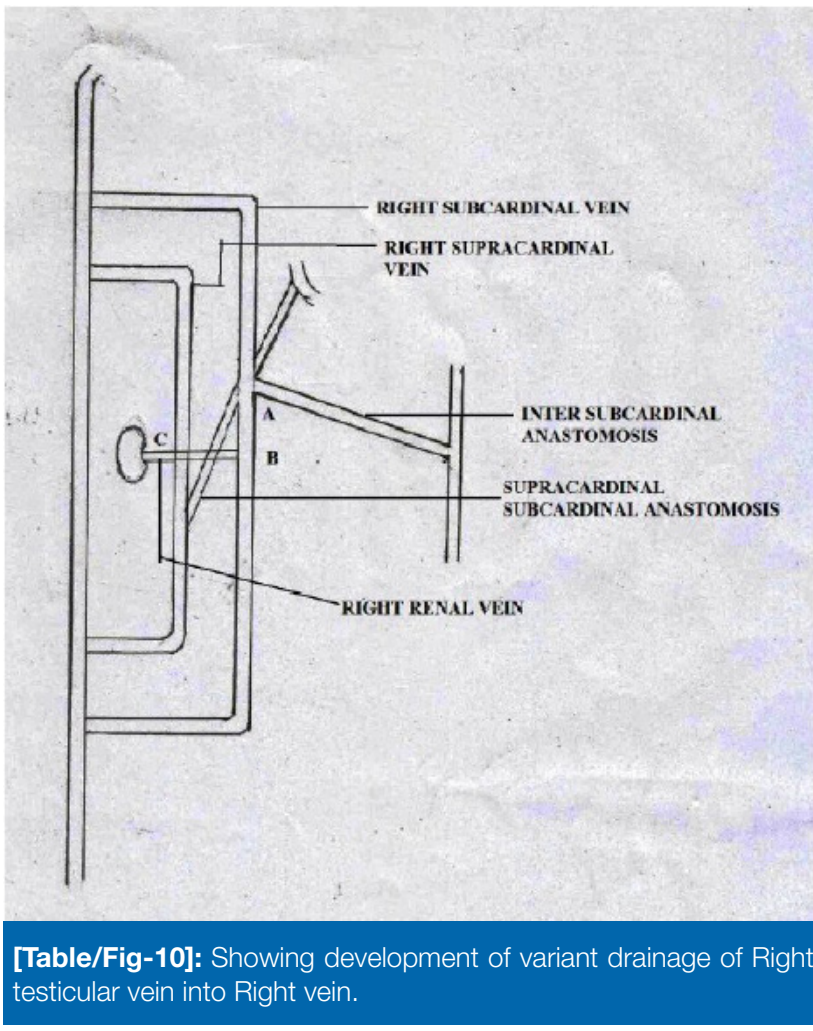

b. Multiple left renal arteries may be explained ontogenically as in case of multiple right renal arteries (vide supra).

\section{c. Retroaortic left renal veins}

Gupta et al., [1] have thrown a flood of light on the ontogeny of this condition. Accordingly, the left renal vein develops from the intersubcardinal anastomosis which originally is in the form of a network out of which some channels pass anterior to aorta and some posterior to it. Usually the posterior channels disappear and the anterior one persists but in the retro-aortic left renal vein it is the posterior channel which persists and anterior one disappears.

\section{PHYLOGENY}

Development of kidney is said to be the best example of the dictum, "ontogeny repeats phylogeny" i.e. during ontogeny 
of human kidney it passes through different stages of development in lower animals.

a. Multiple Renal arteries- Gupta et al., [1] conducted a comparative study of renal arteries in different vertebrates and found that in frogs 5-6 pairs of renal arteries are arising from dorsal aorta. Similarly $\geq 3$ pairs of renal arteries arise from dorsal aorta in lizards and 3 pairs in domestic fowl. However, in the later the middle and caudal pairs arise from ischiatic artery instead of aorta. This led them to explain the occurrence of multiple renal arteries on the basis of phylogeny as these may be persistence of phylogenetic traits.

\section{CLINICAL IMPLICATIONS}

\section{a. Multiple Renal Arteries}

Multiple renal arteries / accessory renal arteries are usually the end arteries and if an accessory renal artery is damaged or ligated, the part of kidney supplied by it is likely to be necrosed [8]. These have also been implicated in renal hypertension by Derrik and Hooks [38]. There is always a danger of damage to accessory renal artery during surgery. Also, the lower polar arteries which typically pass anterior to ureter are associated with a relatively high incidence of hydro nephrosis as a result of obstruction of ureter.

Accessory renal artery is related to the segmental arteries, so the risk of bleeding during segmental ischemia, postoperative hypertension and during urological surgery increases. As the demand of kidney donation has increased, so it is essential to rule out the possibility of donors with multiple renal arteries. Selective renal angiography should be performed when renovascular intervention is considered. Even though being considered as relative contraindication allograft with multiple renal arteries can be implanted with short and long term results comparable to those with single renal arteries by using surgical technique that best fits a particular situation [1].

Intraoperative bleeding and postsurgical complications are often observed as a result of multiple renal arteries. A careful suturing is required by surgeons in such cases [39].Their knowledge is essential before transplantation surgery where microvascular techniques are employed to reconstruct renal arteries [40].

\section{b. Origin of right testicular artery from right renal artery}

The knowledge of anatomy of gonadal arteries becomes more important because of development of new operative techniques for varicocele and undescended testis [41]. Origin and course of testicular artery must be carefully identified in microvascular autotransplant of intra abdominal testis. To prevent testicular atrophy testicular artery must be preserved during varicocelectomy [42]. During laproscopic surgeries an unfamiliar anatomy may lead to many complications. A testicular artery arising from renal artery can lead to testicular infarction during palliative trans-catheter ethanol embolization for intermittent gross haematuria [43]. So an arteriography or dopler ultrasound examination of renal hilum prior to any surgery in this region becomes all the more important.

This type of variant origin of right testicular artery may pose difficulty even during renal transplant. Such arteries may be involved in orthopaedic procedures involving lumbar spine. The testicular artery may get compressed between renal artery and renal vein leading to ischaemia of testis. If overlooked renal origin of testicular artery might produce grave clinical consequences. So their knowledge is a must not only for surgeons, urologists and radiologists but also for clinicians during endovascular embolization and angioplasties.

\section{c. Right testicular vein joining right renal vein}

One of the causes of varicocoele being more common on left side is drainage of left testicular vein into left renal vein at right angle. In patients when right testicular vein drains into right renal vein, chances of varicocele on right side will definitely increase.

\section{d. Multiple renal veins}

An anatomical knowledge of multiple renal veins and arteries is of extreme importance to surgeons operating in this region during renal transplant surgeries. Multiple renal veins may increase the surgical morbidity when placement of an IVC filter is considered [44]. Also on account of thinness of their wall and a lack of pulsation, the supernumerary veins increase the hazards of renal surgeries [45].

\section{e. Retroaortic left renal vein}

It may be compressed between aorta and the lumbar spine, leading to left renal venous hypertension, the condition being known as posterior nutcracker syndrome and manifested by left flank and abdominal pain, with or without haematuria $[31,33]$.

Compression of the RA-LRV can cause left renal vein to left gonadal vein reflux, resulting in lower limb varices and varicocoele, which may produce difficulties in spermatogenesis and may lead to infertility[30,32,33]. The RA-LRV has been also associated with pelvic congestion syndromes in females, which is characterised by lower abdominal pain, dysmenorrhoea, dyspareunia, vulval, gluteal or thigh varices and emotional disturbances [33].

\section{CONCLUSION}

It was a unique case with multiple genitourinary vascular anomalies all present in one person. Though all these variations are reported, but individually not together in one case. Further the ontogenic and phylogenic basis of all the variants along with their clinical implications are discussed.

\section{REFERENCES}

[1] Gupta A, Gupta R, Singla RK. The accessory renal arteries: a comparative study in vertebrates with its clinical implications. $J$ Cl and Diag Res. 2011; 5(5):970-73.

[2] Graves FT. The aberrant renal artery. J Anat. 1956; 90: 553-58. 
[3] Rupert RR. Further study of irregular kidney vessels as found in hundred eighteen cadavers. Surg Gynaecol Obstet. 1915; 21: 471-80.

[4] Eisendrath DN. The relation of variations in renal vessels to phylotomy and nephrectomy. Am J Surg. 1920; 71: 723-43.

[5] Anson BJ and Kurth LE. Common variations in the renal blood supply. Surg Gynaecol Obstet. 1955; 100: 157-62.

[6] Merklin RJ, Michel NA. The variant renal and suprarenal blood supply with data on the inferior phrenic, ureteral and gonadal arteries. Int Coll Surg. 1958; 29:41-76.

[7] Bergman RA, Afifi AK, Miyauchi R. Virtual hospital: Illustrated encyclopedia of abdominal aorta 2000; http//www.virtualhospital.com.

[8] Nayak S. Presence of accessory renal artery and kinking of aorta due to the abnormal origin of renal arteries. The Internet $J$ of Biol Anthropol. 2007; I1(2): 1-6.

[9] Saldarriaga S, Perez AF, Balesteros LE. A direct anatomical study of additiona renal arteries in a Colombian Meslizo population. Folia Morphol. 2008; 67(2): 129-34.

[10] Budhiraja V, Rastogi R, Asthana AK. Renal artery variations: embryological basis and surgical correlation. Rom J morphol and embryo. 2010; 51(3): 53336.

[11] Bergman RA, Cassell MD, Sahinoglu K, Heidger PM Jr. Human doubled renal and testicular arteries. Ann Anat.1992:174:313-15.

[12] Notkovich $\mathrm{H}$. Variation of testicular and ovarian arteries in relation to the renal pedicle. Surg Gynecol Obstet.1956; 103:487-95.

[13] Lippert H, Pabst R. In: Arterial Variations in Man, Classification and Frequency. Bergman JF, editor. Verlag, Munchen.1985: 25-29.

[14] Ravery V, Cussenol O, Desgrandchamps F, Teillac P, Martin-Bouyer Y, Lassau JP et al. Variations in arterial blood supply and the risk of haemorrhage during percutaneous treatment of lesions of the pelviureteral junction obstruction: report of a case of testicular artery arising from an inferior polar renal artery. Surg Radiol Anat.1993;15: 355-59.

[15] Asala S, Chaudhary SC, Masumbuko-Kahamba N, Bidmos M. Anatomical variations in the human testicular blood vessels. Ann Anat. 2001;183:545-49.

[16] Cicekcibasi AE, Salbacak A, Seker M, Ziylan T, Buyukmumcu M, Uysal II. The origin of gonadal arteries in human fetuses: anatomical variations. Ann Anat. 2002; 184:275-79

[17] Pai MM, Vadgaonkar R, Rai R, Nayak SR, Jiji PJ, Ranade, A et al. A cadaveric study of the testicular artery in the South Indian population. Singapore Med J. 2008; 49(7): 551-55.

[18] Bordei P, Sapte E, lliescu D. Double renal arteries originating from the aorta. Surg Radiol Anat. 2004;26: 474-79.

[19] Sylvia S, Kakarlapudi SV, Vollala VR, Potu BK, Jetti R, Bolla SR et al. Bilateral variant testicular arteries with double renal arteries. Cases J. 2009; 2: 114-16.

[20] Soni S, Wadhwa A. Multiple Variations in the paired arteries of abdominal aorta - clinical implications. Experimental Research. 2010, 4(3): 2622-25.

[21] Magotra R, Hamid S, Jabeen N, Raina S, Raina S. Anomalous left testicular artery arising from left accessory renal artery and its clinical implications- a case report. Int J Anat Res. 2013;I1(3): 136-39.

[22] Machnicki A Grzybiak M. Variations in testicular arteries in foetuses and adults. Folia Morphol(Warsz). 1997;56:277-85.

[23] Zimstein (1895): cited by Bergman (2000): Virtual Hospital. Illustrated encyclopedia of human renal arteries; 15-18.

[24] Pick JW, Anson BJ. the renal vascular pedicles: an anatomical study of 430 body halves. Journal of Urology. 1940; 44: 411.
[25] Anson BJ, Caudwell EW, Pick JW, Beaton LE : The blood supply of kidney, suprarenal gland and associated structures. Surg Gynaecol Obstet. 1948; 84: 313-20.

[26] Sharma $P$ and Salwan SK: Anomalous right testicular artery and vein Embryological explanation and clinical implications. JCDR 2011; 5(8): 163133.

[27] Anson BJ, Richardson GA, Minear WL: Variations in the number and arrangement of renal vessels: A study of blood supply of 400 kidney. J Urol.1936; 36:211-19.

[28] Monkhouse WS and Khallique A. The adrenal andrenal veins of mass and their connections with azygous and lumbar veins. J. Anat. 1986; 146: 105-15.

[29] Almagro AM, Garcia VA, Sanjuan VM, Tejada THG de, Montalvo PL. Retroaortic left renal vein: a report of six cases. J Surg Radiol Anat. 1992;14(4):361-66.

[30] Jafarpour M Mofidpour $\mathrm{H}$. Left renal vein variations: a cadaveric study. Med $J$ Iran Hosp. 2002;5(1):25-27.

[31] Mendizabal S, Roman E, Serrano A, Barbel O, Simon J. Left renal vein hypertension syndrome. J Nefrologia. 2005; 25(2):141-46.

[32] Karazincir S, Balci A, Gorur S, Sumbus H, Kiper AN. Incidence of retro-aortic left renal vein in patients with varicocele. J Ultrasound Med. 2007; 26: 60104

[33] Hemlatha K, Narayani R, Moorthi M, Korth MP, Jagadeesan K. Retro-aortic left renal vein and hypertension. Bombay Hosp J. 2008; 50(1): 6-9.

[34] Gupta R, Singla RK. Multiple anomalies in abdominal vasculature- a case report. J R Med Edu and Ethics. 2014; 4(1): 98-102.

[35] Kalsey G, Patnaik WVG, Singla RK. Retro aortic left renal vein. J Anat Soc Ind. 1999: 47(2) 76-79.

[36] Singh, R, Jaiswal, A,Shamal, S. N. and Singh S. P. Variation in the origin of the testicular arteries and drainage of the right testicular vein. Int J Morphol. 2011; 29(2):614-16.

[37] Felix W Mesonephric arteries (aa mesophricae) In : Kiebel F, Mall FP eds. Manual of human embryology. Vol 2, Philaedelphia, Lippincott. 1912; 820-25.

[38] Derrick JR, Hooks CA. Surgical significance of vascular variations in systematic hypertension with social reference to aberrant renal arteries. Journal of Urology. 1962; 87: 273.

[39] Rathod K, Ahmed N, Raut A. Circumaortic renal collar. J Postgrad Med. 2004; 50:77-78

[40] Brannen GE, Bush WH, Correa RJ Jr, Gibbons RP, Cumes DM. Microvascular management of multiple renal arteries in transplantation. J Urol.1982;128:11215.

[41] Dhar P, Lal K. Main and accessory renal arteries - A morphological study. Ital J Anat Embryol. 2005;110: 101-10.

42] Jyothsna P, Mohandas Rao K, Somayaji S, Ashwini L. Multiple vascula anomalies involving testicular, suprarenal arteries and lumbar veins. N Am J Med Sci. 2012;4: 154-56

[43] Siniluoto TM, HelstromPA, Paivansalo MJ, Leinonen AS, Testicular infarction following Ethanol embolisation of renal neoplasm. Cardiovasc Intervent Radiol.1988; 11; 162-64.

[44] Deshpande SH, Bannur BM , Patil BSG. Bilateral multiple renal vessels: a case report. JCDR. 2014; 8(1): 141-45

[45] Gillaspie C, Millar LI, Baskin M. Anomalous renal vessels and their surgical significance. Anat Record. 1916; 11:77-86.

\section{AUTHOR(S):}

1. Dr. Rajan Kumar Singla

2. Dr. Kulbir Kaur

3. Dr. Ravikant Sharma

\section{PARTICULARS OF CONTRIBUTORS:}

1. Professor and Head, Department of Anatomy, GMC Patiala, Amritsar, India.

2. Medical Officer, CHC Verka, District Amritsar, India.

3. Professor and Head, Department of Anatomy, GMC Patiala, Amritsar, India.

\section{NAME, ADDRESS, E-MAIL ID OF THE CORRESPONDING AUTHOR:}

Dr. Kulbir Kaur,

Medical Officer, CHC, Verka District, Amritsar, India.

E-mail: drkkaur@yahoo.co.in

FINANCIAL OR OTHER COMPETING INTERESTS: None.

Date of Publishing: Jan 05, 2016 